\title{
Synthesis, Characterization of Cellulose Grafted N-Oxide Reagent and Its Application in Oxidation of Alkyl/Aryl Halides
}

\author{
Inderjeet Kaur*, Poonam K. Dhiman \\ Department of Chemistry, H. P. University, Shimla, India \\ E-mail:ij_kaur@hotmail.com,poonudg@yahoomail.com \\ Received March 19, 2011; revised March 28, 2011; accepted April 2, 2011
}

\begin{abstract}
Oxidation of aliphatic and aromatic halides by N-oxide functionalities supported on 4-vinyl pyridine, (4-VP), grafted cellulose is reported in the present manuscript. Synthesis of graft copolymer of cellulose and poly 4 -vinyl pyridine, poly(4-VP), has been carried out using ceric ions as redox initiator. Post-grafting treatment of CellO-g-poly(4-VP) with $30 \% \mathrm{H}_{2} \mathrm{O}_{2}$ in acetic acid gives Cellulose-g-poly(4-VP) N-oxide, the polymeric supported oxidizing reagent. The polymeric support, CellO-g-poly(4-VP) N-oxide, has been used for oxidation of different alkyl/aryl halide such as 1-bromo-3-methyl butane, 2-bromo propane, 1-bromo heptane and benzyl chloride. The polymeric reagent was characterized by IR and thermo-gravimetric analysis. The oxidized products were characterized by FTIR and $\mathrm{H}^{1} \mathrm{NMR}$ spectral methods. The reagent was reused for the oxidation of a fresh alkyl/aryl halides and it was observed that the polymeric reagent oxidizes the compounds successfully but with little lower product yield.
\end{abstract}

Keywords: Cellulose, 4-Vinyl Pyridine, Graft Co-Polymerization, Cellulose Supported N-Oxide, Oxidation, Thermo-gravimetric Analysis

\section{Introduction}

Preparation of chemically modified polymer surfaces with controllable structures is an area of current research, having both theoretical and practical interest [1]. The objective is to devise mild techniques of primary surface functionalization with a high degree of chemo- and topological selectivity. The primary functional groups on the surface should be capable of undergoing a variety of organic chemical transformations under mild conditions, thus enabling creation of novel secondary surface functionalities.

Efficient methods for the conversion of alcohols to aldehydes, ketones or carboxylic acids under mild conditions have been developed, using TEMPO $(2,2,6$, 6-tetramethyl-1-piperidinyloxy), (I), as a catalyst and

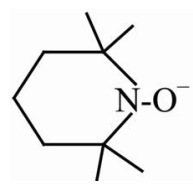

(I) stoichiometric amounts of inexpensive, safe and easy to handle oxidants such as bleach [2], [bis(acetoxy) iodo] benzene (BAIB) [3], trichloroisocyanuricacid (TCCA) [4], oxone [5] or iodine [6].

However, separation of the products from TEMPO could require lengthy workup procedures, especially when reactions are run on large scale [7]. To solve this problem, TEMPO residue has been successfully immobilized to polymeric supports both inorganic [8] and organic polymers [9], affording heterogeneous catalysts which are readily separated from the reaction mixtures but are usually far less versatile than the homogeneous TEMPO [10]. The use of heterogeneous catalysts in the liquid phase, however, offers several advantages over homogeneous ones, such as ease of recovery and recycling, atom utility and enhanced stability [11]. TEMPO anchored to poly (ethylene glycol) (PEG) has been prepared by Pozzi et al. [12] and its catalytic activity in the chemoselective oxidation of alcohols with stoichiometric amounts of organic or inorganic oxidants has been investigated. The PEG-TEMPO is a new metal free catalyst and exhibits high activity. It can be easily removed from 
the reaction mixture and can be reutilized number of times.

Miyazawa and Endo [13] reported the synthesis of soluble and insoluble polystyrene type polymers featuring TEMPO residue and used it in combination with potassium ferricyanide in alkaline water/acetonitrile as solvent for the oxidation of benzyl alcohol to benzaldehyde at room temperature. Leadbeater and Scott [14] prepared a resin-bound cobalt phosphine complex and assessed its use in catalytic oxidation and acid anhydride synthesis. Gopinathan et al. [15] described a simple, mild and high yielding procedure for the iodination of allylic, benzylic and other primary alcohols using a combination of iodine imidazole on polymer supported triphenylphosphine. Poly(ethylene glycol) based aqueous biphasic systems (PEG-ABSs) have been investigated as tunable reaction media to control the oxidation of cyclohexene to adipic acid with hydrogen peroxide [16].

Divinyl benzene cross-linked polystyrene supported $\beta$-diketone linked complexes of Mn (II) have been prepared, characterized and their role as catalysts in the oxidation of alcohols by $\mathrm{Cr}$ (VI) has been invesitigated [17]. New reagents and polymer supported versions are highlighted which facilitate the use of hypervalent iodine compounds in oxidation and rearrangement reactions [18]. A three-step preparation of a polymer-supported iodoxybenzoic acid (PSIBX) reagent from poly(p-methyl styrene) has been reported and it was used for the efficient oxidation of a series of alcohols to the corresponding aldehydes [19]. An efficient procedure for the highly selective oxidation of leucomycines to the corresponding 16-membered 9- and 13-oxomacrolides using hypervalent iodine reagents in solution and on solid support has been reported [20].

A polymer support, (1-hydroxy-1,2-benziodoxol$3(1 \mathrm{H})$-one-1-oxide), was synthesized and used to oxidize alcohols selectively to the corresponding ketones and aldehydes [21].

It is well known that pyridine has wide applicability in organic synthesis by itself or in conjunction with other reagents. Both poly(2-vinyl pyridine) and poly(4-vinyl pyridine) form complexes with various transition metal ions $[22,23]$. Therefore, it seems that in case of grafted pyridines, the presence of pendant reactive pyridyl group nitrogen on the repeating unit of polyvinyl pyridine will make the grafted polymer useful as a reagent. Recently we reported on the oxidation and reduction reactions using polymer supported reagents developed from cellulose grafted with 4-vinyl pyridine [24].

Thus, it is evident from literature that different polymeric supports carrying specific functional groups are used for specific reactions. In view of this, in the present manuscript, synthesis of simple polymeric support from cellulose graft copolymerized with 4-vinyl pyridine i.e. Cellulose-g-poly (4-vinyl pyridine) carried out by post grafting reaction is discussed. The respective polymeric reagent was utilized for oxidation of some alkyl halides such as 1-bromo-3-methyl butane, 2-bromo propane and 1-bromo heptane and aryl halide such as benzyl chloride. Structure - reactivity relationship between the reactant and the reagent has been evaluated and discussed.

\section{Experimental}

\subsection{Synthesis of Cellulose Based Poly(4-VP)}

The details of the synthesis of 4-vinyl pyridine grafted cellulose has been discussed in our previous papers $[24,25]$.

Optimum conditions pertaining to maximum percentage of grafting have been evaluated as a function of concentration of the initiator, monomer, and nitric acid, amount of water, time and temperature. Maximum percentage of grafting $(585 \%)$ was obtained using 0.927 moles $/ \mathrm{L}$ of $4-\mathrm{VP}$ and 0.018 moles/L of ceric ammonium nitrate $(\mathrm{CAN})$ in $120 \mathrm{~min}$. at $45^{\circ} \mathrm{C}$.

\subsection{Synthesis of Cellulose Based N-oxide Reagent}

\section{1) Materials and Method}

CellO-g-poly (4-VP), referred to as Resin I, was used as the base polymer. Acetic acid (Reagent Grade) and $30 \% \mathrm{H}_{2} \mathrm{O}_{2}$ (S.D. Fine Chem. Ltd.) were used as received. Benzene-Methanol in different proportions was used as the solvent for TLC.

\section{2) Procedure}

A suspension of $1 \mathrm{gm}$ of Resin $\mathrm{I}$ in $8 \mathrm{~mL}$ acetic acid was treated with $5.3 \mathrm{~mL}$ of $\mathrm{H}_{2} \mathrm{O}_{2}(30 \%)$ and kept at room temperature under stirring for $4 \mathrm{~h}$. After the stipulated time, the reagent, CellO-g-poly(4-VP) N-oxide, referred to as Resin II, was collected and dried.

\subsection{Oxidation of Alkyl/Aryl Halides}

The following general method was followed for the oxidation reactions:

Freshly prepared CellO-g-poly(4-VP) N-oxide, Resin II, $0.500 \mathrm{~g}$ in $10 \mathrm{~mL}$ of benzene was placed in a round bottomed flask and to this was added $5 \mathrm{~mL}$ of the reactant i.e. alkyl/aryl halide. The reaction mixture was heated under reflux and continuous stirring. The progress of the reaction was monitored on TLC. After the completion of the reaction, the resin was filtered off and the products were separated by fractional distillation. 


\section{Characterization}

The characterization of CellO-g-poly(4-VP) N-oxide was carried out by FTIR spectroscopy and thermo gravimetric analysis (TGA) and was compared to that of cellulose and CellO-g-poly(4-VP). FTIR spectra have been obtained on Beckman spectrophotometer. TGA have been taken on LINSEIS, L 81-11 Germany made, in air at the heating rate of $10{ }^{\circ} \mathrm{C} / \mathrm{min}$. The oxidation products of al$\mathrm{kyl} / \mathrm{aryl}$ halides to respective aldehydes/ketones have been characterized by IR and NMR spectroscopic methods. $\mathrm{H}^{1} \mathrm{NMR}$ was obtained on JEOL FT-NMR AL 300 $\mathrm{MHz}$ Spectrophotometer.

\subsection{FTIR Spectroscopy}

The FTIR data of CellO-g-poly(4-VP) N-oxide (Figure 1), in addition to the regular bands due to $v_{\mathrm{C}-\mathrm{H}}$ str. at $2952.3 \mathrm{~cm}^{-1}$ and $v_{\mathrm{C}-\mathrm{O}}$ str. at $1352-1032 \mathrm{~cm}^{-1}$ of cellulose and $v_{\mathrm{C}=\mathrm{C}}$ and $v_{\mathrm{C}=\mathrm{N}}$ str. at $1644-1381 \mathrm{~cm}^{-1}$ of pyridine ring of grafted poly(4-VP) (Table 1), shows a characteristic peak for the ammonium salt i.e. at $2392.3 \mathrm{~cm}^{-1}$ which confirms that CellO-g-poly(4-VP) is converted into ammonium salt with oxide anion attached to it. In case of quaternization, the signal for $v_{\mathrm{C}=\mathrm{N}}$ is shifted from $1575.1 \mathrm{~cm}^{-1}$ to $1644.3 \mathrm{~cm}^{-1}$ and a new strong signal at $1209.2 \mathrm{~cm}^{-1}$ due to $\mathrm{N}$-oxide has appeared, thus proving the chemical transformation. Similar observations were made by Zupan, Sket and Johar [25] during the studies on synthesis and preparation of cross-linked 4-vinyl pyridine-styrene-halogen complexes.

\subsection{Thermo-gravimetric Analysis}

The primary thermograms of cellulose, CellO-g-poly (4-VP) and CellO-g-poly(4-VP) N-oxide are compared. The initial decomposition temperature (IDT), final decomposition temperature (FDT) and decomposition temperature (DT) at every $10 \%$ weight loss are presented in Table 2. It is observed from the thermo grams that unmodified cellulose shows a single stage of decomposition

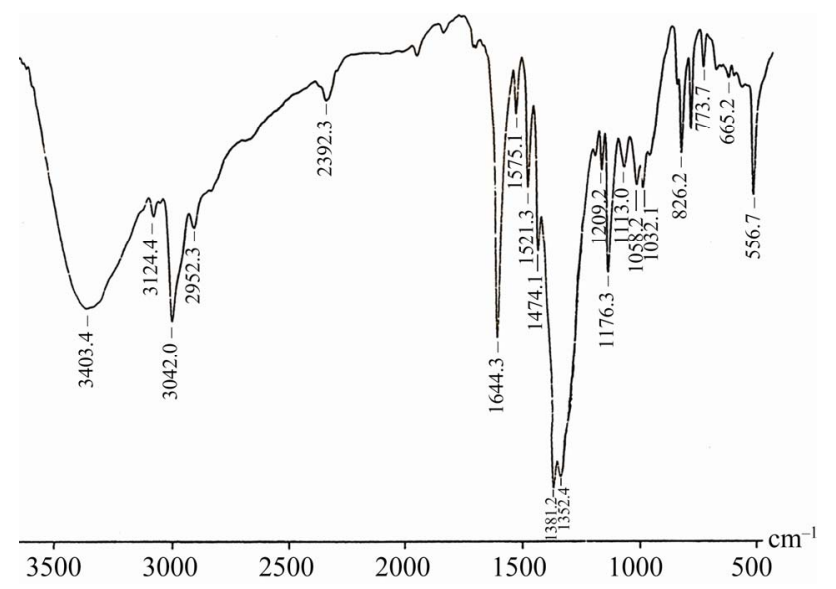

Figure 1. FTIR spectrum of CellO-g-poly(4-VP)N-oxide.

while the 4-VP grafted cellulose shows double stage of decomposition.

In case of the primary thermogram of cellulose the thermal degradation of cellulose proceeds essentially through two types of reactions. At lower temperatures i.e. between $120^{\circ} \mathrm{C}-250^{\circ} \mathrm{C}$, there is a gradual degradation, which includes depolymerization, hydrolysis, oxidation, dehydration and decarboxylation. At higher temperatures $\left(250^{\circ} \mathrm{C}-397^{\circ} \mathrm{C}\right)$, a rapid volatilization occurs losing $\mathrm{H}_{2} \mathrm{O}$, $\mathrm{CO}_{2}$ and $\mathrm{CO}$ molecules with the formation of glucosan. The percent residue is $13.08 \%$.

Thermal decomposition of grafted cellulose i.e. CellO-g-poly(4-VP) proceeds in two stages. The first stage of decomposition lying between $170^{\circ} \mathrm{C}-205^{\circ} \mathrm{C}$ during which the pendant grafted chains of poly(4-VP) are degraded with up to $35 \%$ weight loss beyond which the second stage of decomposition starts and goes upto $375^{\circ} \mathrm{C}$ and continues up to $584.5^{\circ} \mathrm{C}$ with further loss of $45 \%$ weight. High percentage $(26.67 \%)$ of residue is left after the decomposition.

In case of CellO-g-poly(4-VP) N-oxide (Figure 2), it is observed from the primary thermogram that the cellulose graft $\mathrm{N}$-oxide shows a single stage decomposition as observed for cellulose. During the initial rise in temperature from $80^{\circ} \mathrm{C}$ to $283.3^{\circ} \mathrm{C}$, from where the initial

Table 1. FTIR spectroscopy of CellO-g-poly(4-VP).

\begin{tabular}{|c|c|c|c|c|c|c|}
\hline Sample & Structure & $\begin{array}{c}\mathrm{C}-\mathrm{H} \\
\mathrm{v}, \mathrm{cm}^{-1}\end{array}$ & $\begin{array}{c}=\mathrm{C}-\mathrm{H} \\
\mathrm{v}, \mathrm{cm}^{-1}\end{array}$ & $\begin{array}{c}\mathrm{C}=\mathrm{C} \\
\mathrm{v}, \mathrm{cm}^{-1}\end{array}$ & $\begin{array}{c}\mathrm{C}=\mathrm{N} \\
\mathrm{v}, \mathrm{cm}^{-1}\end{array}$ & $\begin{array}{c}\mathrm{C}-\mathrm{O} \\
\mathrm{v}, \mathrm{cm}^{-1}\end{array}$ \\
\hline Cellulose & ${ }_{2} \mathrm{OH}$ & $\begin{array}{c}2902.5 \\
1430.7 \text { (def.) } \\
1376.0 \text { (def.) }\end{array}$ & & & & $\begin{array}{c}1341- \\
1029\end{array}$ \\
\hline CellO-g-poly(4-VP) & $\mathrm{CH}_{2}-\mathrm{C}$ & & 3043.2 & $\begin{array}{l}1644.7 \\
1521.4 \\
1352.6\end{array}$ & $\begin{array}{l}1644.7 \\
1521.4 \\
1352.6\end{array}$ & $\begin{array}{c}1176- \\
1031\end{array}$ \\
\hline
\end{tabular}




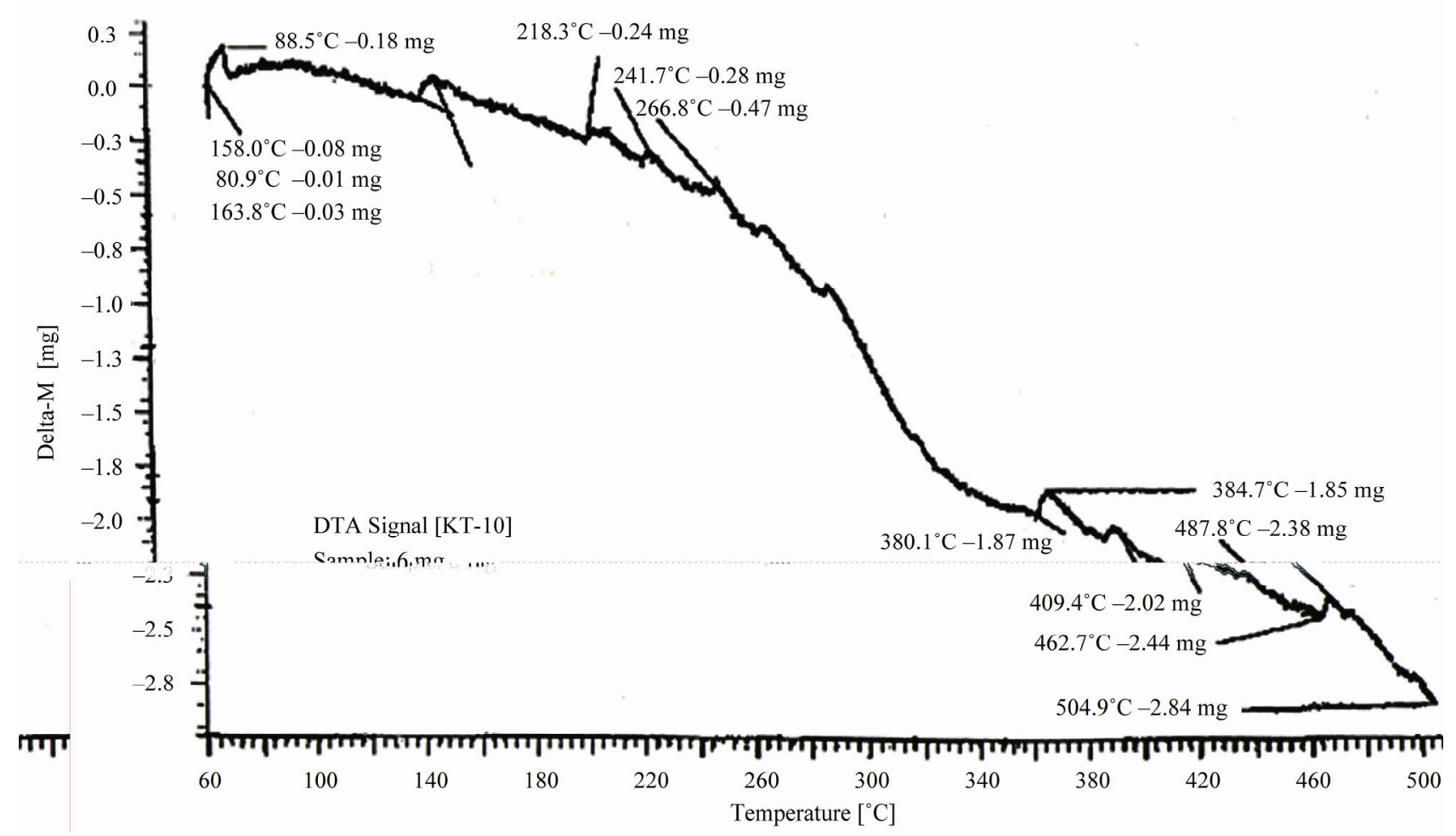

Figure 2. Primay thermogram of CellO-g-poly(4-VP) N-oxide.

Table 2. Thermogravimetric data of cellulose and cellulose g-poly (4-VP) N-Oxide.

\begin{tabular}{|c|c|c|c|c|c|c|c|c|c|c|c|c|}
\hline \multirow{2}{*}{ Sample } & \multirow{2}{*}{$\begin{array}{c}\text { IDT }\left({ }^{\circ} \mathrm{C}\right) \\
\text { (\%wt. } \\
\text { Loss) }\end{array}$} & \multirow{2}{*}{$\begin{array}{c}\text { FDT }\left({ }^{\circ} \mathrm{C}\right) \\
\text { (\%wt. } \\
\text { Loss) }\end{array}$} & \multicolumn{9}{|c|}{ DT at every $10 \%$ wt. Loss $\left({ }^{\circ} \mathrm{C}\right)$} & \multirow{2}{*}{$\begin{array}{l}\text { Percent } \\
\text { residue }\end{array}$} \\
\hline & & & $10 \%$ & $20 \%$ & $30 \%$ & $40 \%$ & $50 \%$ & $60 \%$ & $70 \%$ & $80 \%$ & $90 \%$ & \\
\hline $\begin{array}{l}\text { Unmodified } \\
\text { Cellulose }\end{array}$ & $\begin{array}{c}319.35 \\
(4.28 \%)\end{array}$ & $\begin{array}{c}360 \\
(65.62 \%)\end{array}$ & 330.65 & 339.68 & 346.45 & 350.97 & 353.23 & 366.77 & 393.87 & 500.00 & - & $13.08 \%$ \\
\hline $\begin{array}{c}\text { CellO-g-poly } \\
\text { (4-VP) } \\
\text { N-Oxide }\end{array}$ & $\begin{array}{c}283.3 \\
(10.53 \%)\end{array}$ & $\begin{array}{c}354.3 \\
(32.11 \%)\end{array}$ & 271.43 & 315.7 & 348.57 & 462.85 & - & - & - & - & - & $52.66 \%$ \\
\hline
\end{tabular}

decomposition begins, the decomposition is very slow with a small loss in weight $(10 \%)$. There may be some loss due to moisture desorption during this phase. Beyond the initial decomposition, $\left(283.3^{\circ} \mathrm{C}\right)$, the degradation is fast with a large temperature difference between each $10 \%$ wt, loss $\left(44.27^{\circ} \mathrm{C}\right.$ between $10 \%$ to $20 \%$, $32.87^{\circ} \mathrm{C}$ between 20 to $30 \%$ and $117.28^{\circ} \mathrm{C}$ between $30 \%$ to $40 \%$ wt. loss). The temperature difference between each $10 \%$ weight loss of cellulose up to $70 \%$ is very low, lying between $2.26^{\circ} \mathrm{C}$ to $27.10^{\circ} \mathrm{C}$ and moving from $70 \%$ weight loss to $80 \%$ weight loss this difference increases to $106.13^{\circ} \mathrm{C}$ indicating the formation of stable glucosan. In case of the grafted sample, although the decomposition values are very low as compared to that for unmodified cellulose, the temperature difference between each $10 \%$ weight loss is very high, beyond $30 \%$ wt. loss the value difference lies between $47.5^{\circ} \mathrm{C}$ to $105^{\circ} \mathrm{C}$.
Final decomposition begins at $354.3^{\circ} \mathrm{C}$ with only $32.11 \%$ wt. loss. The percent residue left is very high $(52.66 \%)$.

Higher DT values, large temperature difference between each $10 \%$ wt. loss and high percent residue indicate a very good thermal stability of CellO-g-poly(4-VP) $\mathrm{N}$-oxide as compared to cellulose and CellO-g-poly (4-VP).

\section{Results and Discussion}

\subsection{Synthesis of Polymeric Support}

Synthesis of graft co-polymer of cellulose essentially involves generation of active sites on the cellulose backbone upon which a suitable monomer is polymerized. In 
the present work grafting onto cellulose is carried out in the presence of 4-VP, by chemical method using CAN as redox initiator. The detailed mechanism has been discussed elsewhere [24]. In general the mechanism of the transition metal ion induced grafting process, where glycol groups are involved, using $\mathrm{Ce}(\mathrm{IV})$ salt, can be represented as follows:

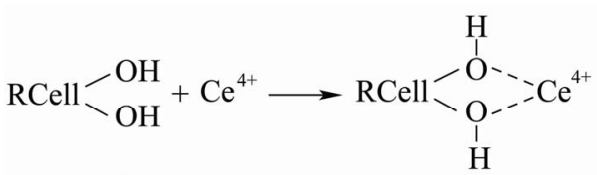

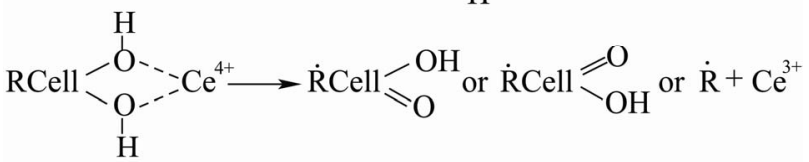

$\dot{\mathrm{R}}+\mathrm{M} \longrightarrow$ Graft copolymer

The presence of radicals on the cellulose backbone has been confirmed by ESR measurements [26]. Monomer is also known to form complex with ions, which dissociate to give monomer radical that propagates to give polymeric chains. These growing polymeric chains attach to the radical site on cellulose to give graft copolymer or terminate to give homopolymer.

$$
\begin{aligned}
& \mathrm{M}+\mathrm{Ce}^{4+} \longrightarrow \text { Complex }=\dot{\mathrm{M}}+\mathrm{Ce}^{3+}+\dot{\mathrm{H}} \\
& \dot{\mathrm{M}}+\mathrm{nM} \longrightarrow(\dot{\mathrm{M}})_{\mathrm{n}+1} \\
& \dot{\mathrm{R}}+(\dot{\mathrm{M}})_{\mathrm{n}+1} \longrightarrow \mathrm{R}-(\mathrm{M})_{\mathrm{n} 11} \quad(\text { Graft copolymer }) \\
& (\dot{\mathrm{M}})_{\mathrm{n}+1}+(\dot{\mathrm{M}})_{\mathrm{n}+1} \longrightarrow(\mathrm{M}-\mathrm{M})_{2 \mathrm{n}+2} \quad \text { (Homopolymer) }
\end{aligned}
$$

The effect of different reaction parameters such as [CAN], $\left[\mathrm{HNO}_{3}\right],[4-\mathrm{VP}]$, amount of water, temperature, and reaction time on percentage of grafting of 4-VP onto cellulose has been studied and maximum percentage of grafting $(585 \%)$ was obtained at the following reaction conditions.

Table 3. Optimum conditions for grafting 4-vinyl pyridine onto cellulose.

\begin{tabular}{|c|c|c|c|c|c|c|}
\hline $\begin{array}{c}\text { Cellulose } \\
(\mathrm{g})\end{array}$ & $\begin{array}{c}{[\mathrm{CAN}]} \\
(\mathrm{mol} / \mathrm{L})\end{array}$ & $\begin{array}{c}{\left[\mathrm{HNO}_{3}\right]} \\
(\mathrm{mol} / \mathrm{L})\end{array}$ & $\begin{array}{c}\mathrm{H}_{2} \mathrm{O} \\
(\mathrm{mL})\end{array}$ & $\begin{array}{c}\text { Temp. } \\
\left({ }^{\circ} \mathrm{C}\right)\end{array}$ & $\begin{array}{c}\text { Time } \\
(\mathrm{min} .)\end{array}$ & $\begin{array}{c}{[4-\mathrm{VP}]} \\
(\mathrm{mol} / \mathrm{L})\end{array}$ \\
\hline 0.200 & 0.018 & 0.797 & 20 & 45 & 120 & 0.927 \\
\hline
\end{tabular}

On treatment 4-vinyl pyridine grafted cellulose, CellO-g-poly(4-VP), with $\mathrm{H}_{2} \mathrm{O}_{2} / \mathrm{AcOH}$ polymeric reagent, CellO-g-poly(4-VP) N-oxide was obtained and was used for the oxidation reactions.

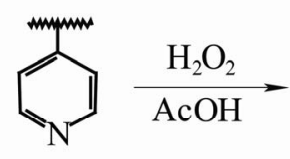

(Resin I)<smiles>CC(C)(C)c1cc[n+]([O-])cc1</smiles>

(Resin II)

\subsection{Oxidation Reactions}

Oxidations of alkyl/aryl halides were carried out by CellO-g-poly(4-VP) N-oxide. The time of reaction, percent yield and $\mathrm{Rf}$ values for reactants and products are presented in Table 4.

Few reagents are available for the direct oxidation of alkyl halides into carbonyl compounds. Perhaps the best known reagent for this transformation is DMSO. Johnson and Pelter [27] showed that DMSO at $150^{\circ} \mathrm{C}$ oxidized 1 -iodooctane rapidly to aldehyde in $74 \%$ yield. Lower yields were obtained with secondary iodides or primary chlorides. By adding silver tetrafluoroborate to the reaction mixture Ganem and Boeckman [28] obtained 83\% yield of octanal from 1-bromooctane. Another reagent which is available but is seldom used for this type of transformation is trimethylamine oxide [29]. This reagent is potentially very interesting but it affords only $30 \%$ $50 \%$ yields of highly contaminated aldehydes from corresponding primary alkyl iodides. It also requires scrupulously anhydrous conditions.

Significant improvements in oxidation were achieved by using insoluble polymer, cross-linked polystyrene containing amine oxide group (I).

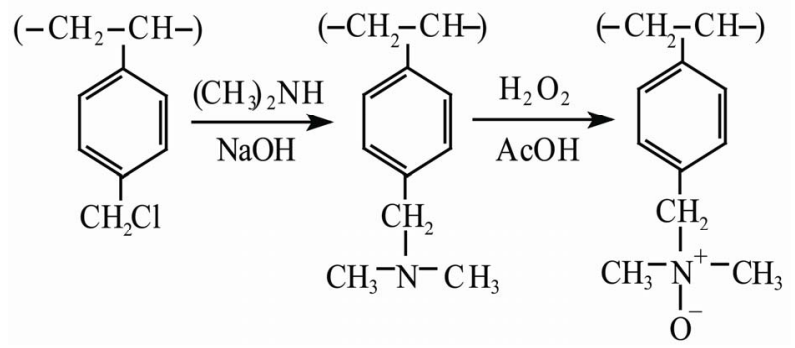

\begin{tabular}{|c|c|c|c|c|c|}
\hline \multirow{2}{*}{ Reactant } & \multirow{2}{*}{ Product } & \multirow{2}{*}{ Time (hrs.) } & \multicolumn{2}{|c|}{ Rf values } & \multirow{2}{*}{ Yield } \\
\hline & & & Reactant & Product & \\
\hline Benzyl chloride & Benzaldehyde & 18 & ------ & 0.75 & $53.4 \%$ \\
\hline 1-Br-3-methyl butane & 3-Methyl butanal & 24 & 0.47 & 0.22 & $30 \%$ \\
\hline 2-Bromopropane & Acetone & 16 & ------ & ------ & $40 \%$ \\
\hline 1-Br-heptane & Heptanal & 38 & 0.90 & 0.40 & $60 \%$ \\
\hline
\end{tabular}

(I)

Table 4. Oxidation of alkyl/aryl halides using CellO-g-poly (4-VP) N-oxide, Resin II, as PS-oxidizing reagent: (Resin II = 500 mg, Solvent $=10 \mathrm{~mL}$, Reactant $=5 \mathrm{~mL}$ ). 
Frechet and co-workers [30] used five fold excess of the polymeric N-oxide (I) for the oxidation of 1-bromoheptane and benzyl chloride to yield $87 \%$ and $95 \%$ of corresponding aldehydes at $70^{\circ} \mathrm{C}$. In the present work, $\mathrm{N}$-oxide functionality supported on a polymeric backbone, CellO-g-poly(4-VP), to carry out oxidation of alkyl/aryl halides has been used. The percent yield of the corresponding aldehydes from 1-bromoheptane and benzyl chloride using CellO-g-poly(4-VP) N-oxide was $60 \%$ and $53.4 \%$ obtained in $38 \mathrm{~h}$ and $18 \mathrm{~h}$ respectively which was less than that obtained by using polymeric $\mathrm{N}$-oxide (I). The low yield may be due to the reason that nitrogen carrying the oxygen is a part of the aromatic ring and thus behaves differently from its alkyl N-oxide (I) counterpart.

\subsection{FTIR Spectroscopy of Oxidized Products}

The FTIR spectra of benzaldehyde (Figure 3) obtained upon oxidation of benzyl chloride, 3-methyl butyraldehyde (Figure 4) from 1-bromo-3-methyl butane, acetone from 2-bromopropane and heptanal from 1-bromoheptane show characteristic peaks for aldehydes/ketones between $1637.2-1733.3 \mathrm{~cm}^{-1}$ due to $v_{\mathrm{C}=\mathrm{O}}$ str.. The aldehydic function of 3-methyl butyraldehyde and heptanal show a doublet for $v_{\mathrm{C}-\mathrm{H}} \mathrm{str}$. in the region between $2859-2962$ $\mathrm{cm}^{-1}$. Several bands in the range $1023-1386 \mathrm{~cm}^{-1}$ due to $\mathrm{C}-\mathrm{CHO}$ skeletal structure are also observed.

\section{4. $H^{1}$ NMR Studies}

In the $H^{1} \mathrm{NMR}$ spectrum of the benzaldehyde obtained by the oxidation of benzyl chloride, a characteristic singlet at $10.00 \delta$ for aldehydic protons is observed in addition to the aromatic protons.

3-Methyl butyraldehyde obtained by the oxidation of 1-bromo-3-methyl butane, have four types of equivalent protons (marked as a, b, c and d).

$$
\begin{gathered}
\mathrm{CH}_{3} \\
\mathrm{CH}_{3} \mathrm{CHCH}_{2} \mathrm{CHO} \\
\text { (a) (b) (c) (d) }
\end{gathered}
$$

The $\mathrm{H}^{1} \mathrm{NMR}$ spectrum accordingly reveals a doublet at $0.97 \delta$ due to $\mathrm{CH}_{3}$ (a) protons, a multiplet at $1.35 \delta$ due to $\mathrm{CH}$ (b) proton and $\mathrm{CH}_{2}$ (c) protons (not splitted) and a triplet at $10.00 \delta$ for aldehydic proton (d).
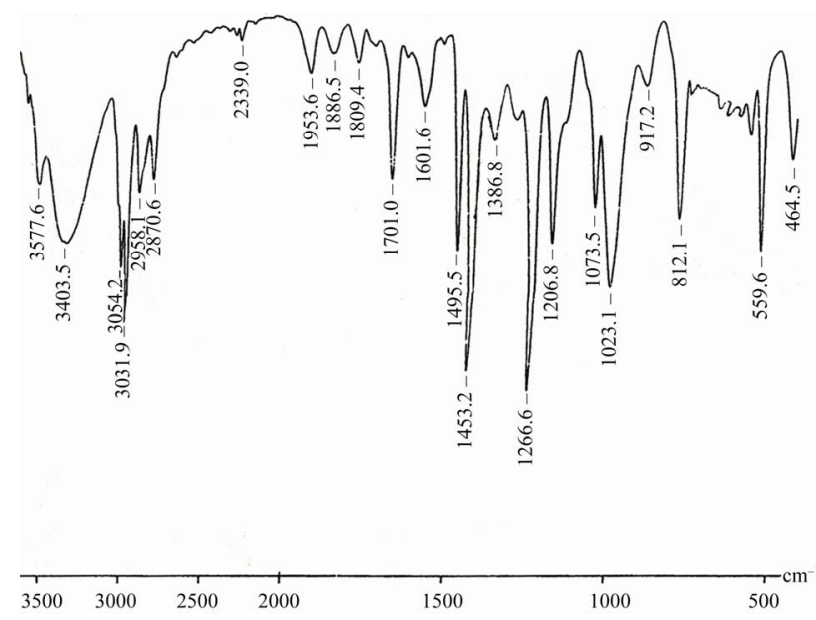

Figure 3. FTIR spectrum of benzaldehyde.

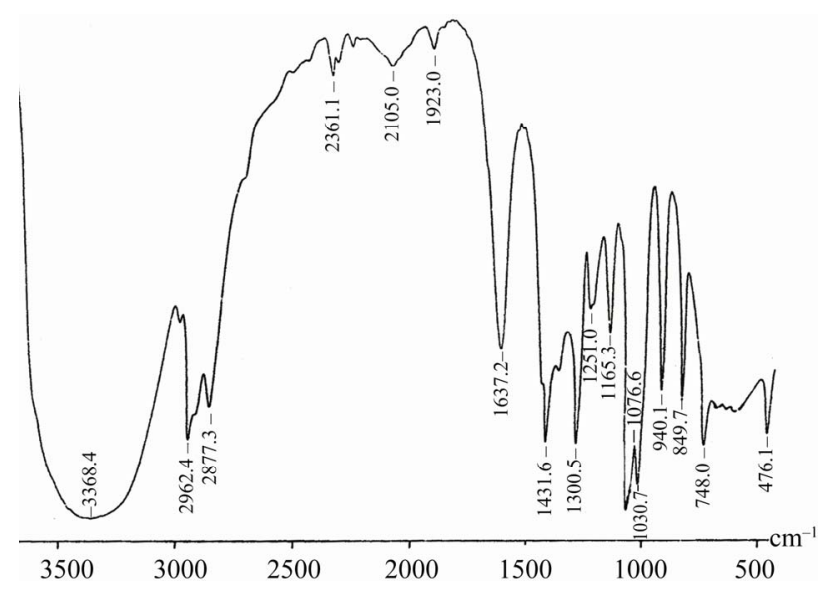

Figure 4. FTIR spectrum of 3-methyl butyraldehyde.

The $\mathrm{H}^{1} \mathrm{NMR}$ spectrum of acetone, (Figure 5), obtained upon oxidation of 2-bromo propane shows a singlet at $1.20 \delta$, equivalent to $6 \mathrm{H}$ due to the methyl protons (a) attached to the carbonyl group.<smiles>CC(C)=O</smiles>

The $\mathrm{H}^{1} \mathrm{NMR}$ spectra of heptanal obtained by the oxidation of 1-bromo heptane is shown in Figure 6. Characteristic triplet at $10.00 \delta$ for aldehydic proton and peaks between $0.90 \delta$ to $2.47 \delta$ for alkyl chain of heptanal are observed. The splitting of the peaks is not so clear due to the overlapping of the peaks.

From the above studies it is, thus, clear that successful<smiles>[R]C([R])[O-]</smiles> 


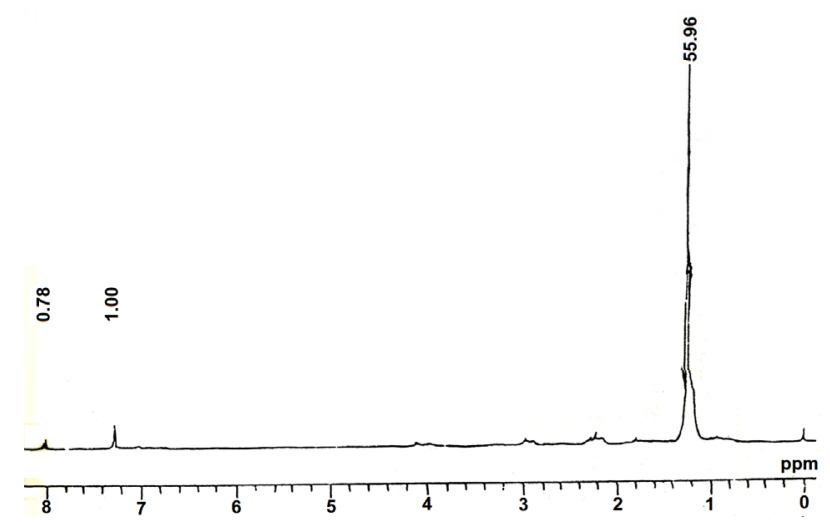

Figure 5. H1 NMR spectrum of acetone.

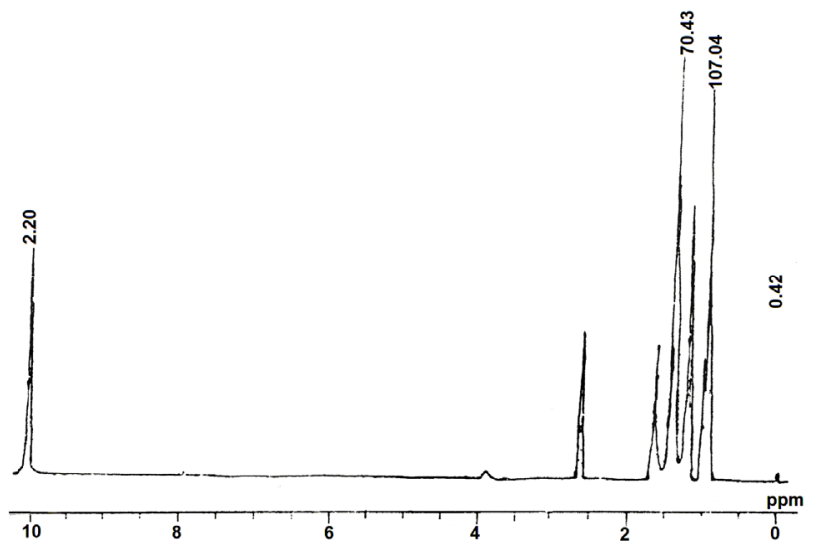

Figure 6. H1 NMR spectrum of heptanal.

oxidations of alkyl/aryl halides using CellO-g-poly(4-VP) $\mathrm{N}$-oxide as PS-oxidizing reagent has been achieved.

\section{Reusability of PS-oxidizing Reagents}

In order to check that whether the polymeric support is reusuable after the reaction, the PS-oxidizing reagents were reused after drying for the oxidation of benzyl chloride. It was observed that the reagent efficiently oxidized the reactant although the yield of the oxidation product was little low (46\%) as compared to the yield $(53.4 \%)$ obtained from freshly prepared polymeric reagent.

The PS-oxidizing reagent could also be easily regenerated by washing with very dilute $\mathrm{HCl}$ solution, fol- lowed by very dilute $\mathrm{NaOH}$ solution and rinsing with water. The washed polymers were treated with subsequent simple organic reagents to introduce respective functional moieties such as N-oxide and then used for further oxidation reactions. Table 5 shows the $\%$ yield of the products obtained by oxidation of benzyl chloride using the used CellO-g-poly(4-VP) N-oxide reagent and the regenerated CellO-g-poly(4-VP) N-oxide polymeric support. The data shows that the percent yield is less with the used PS-oxidizing reagent but it is almost regained after regenerating the polymeric support with respective oxidizing groups.

\section{Conclusion}

The synthesis of simple polymeric support from cellulose graft copolymerized with 4-vinyl pyridine i.e. cellulose-g-poly(4-vinyl pyridine) by carrying out post grafting reaction is discussed. The respective polymeric reagent i.e. CellO-g-poly(4-VP) N-oxide is utilized for oxidation of different alkyl/aryl halide such as 1-bromo-3-methyl butane, 2-bromo propane, 1-bromo heptane and benzyl chloride. The support can be reused and can also be easily regenerated for further oxidations.

\section{References}

[1] G. M. Whitesides and G. S. Ferguson, "Organic Chemistry in Two Dimensions: Surface-functionalized Polymers and Self-assembled Monolayer Films," Chemtracts Organic Chemistry, Vol. 1, 1988, pp. 171-187.

[2] P. L. Anelli, S. Banfi, F. Montanari and S. Quici, "Oxidation of Diols with Alkali Hypochlorites Catalyzed by Oxammonium Salts under Two-phase Conditions," Journal of Organic Chemistry, Vol. 54, No. 12, 1989, pp. 2970-2972. doi:10.1021/jo00273a038

[3] A. de Mico, R. Margarita, L. Parlanti, A. Vescovi and G. Piancatelli, "A Versatile and Highly Selective Hypervalent Iodine (III)/2,2,6,6-tetramethyl-1-piperidinyloxylmediated Oxidation of Alcohols to Carbonyl Compounds," Journal of Organic Chemistry, Vol. 62, No. 20, 1997, pp. 6974-6977. doi:10.1021/jo971046m

[4] L. de Luca, G. Giacomelli, S. Masala and A. Porcheddu, "Trichloroisocyanuric/TEMPO Oxidation of Alcohols under Mild Conditions: A Close Investigation," Journal of Organi Chemistry, Vol. 68, No. 12, 2003, pp. 4999-5001.

Table 5. Oxidation of benzyl chloride using used and regenerated CellO-g-poly(4-VP) N-oxide, Resin II, as PS-oxidizing reagent: (Resin II $=500 \mathrm{mg}$, Solvent $=10 \mathrm{~mL}$, Reactant $=5 \mathrm{~mL})$.

\begin{tabular}{|c|c|c|c|c|}
\hline PS-oxidizing reagent & Reactant & Product & Time (hrs.) & Yield \\
\hline $\begin{array}{l}\text { CellO-g-poly(4-VP)N-oxide } \\
\text { (untreated) }\end{array}$ & Benzyl chloride & Benzaldehyde & 18 & $46 \%$ \\
\hline $\begin{array}{l}\text { CellO-g-poly(4-VP)N-oxide } \\
\text { (treated) }\end{array}$ & Benzyl chloride & Benzaldehyde & 18 & $52 \%$ \\
\hline
\end{tabular}


doi:10.1021/jo034276b

[5] C. Bolm, A. S. Magnus and J. P. Hildebrand, "Catalytic Synthesis of Aldehydes and Ketones under Mild Conditions Using TEMPO/Oxone," Organic Letters, Vol. 2, No. 8, 2000, pp. 1173-1175. doi:10.1021/o1005792g

[6] R. A. Miller and R. S. Hoerrner, "Iodine as a Chemoselective Reoxidant of TEMPO: Application to the Oxidation of Alcohols to Aldehydes and Ketones," Organic Letters, Vol. 5, No. 3, 2003, pp. 285-287. doi:10.1021/o10272444

[7] P. L. Anelli, F. Montanari and S. Quici, "A General Synthetic Method for the Oxidation of Primary Alcohols to Aldehydes," Organic Syntheses, Vol. 69, 1990, pp. 212-219.

[8] T. Fey, H. Fischer, S. Bachmann, K. Albert and C. Bolm, "Synthesis, Characterization and HPLC-applications of Novel Phthalocyanine Modified Silica Gel Materials," Journal of Organic Chemistry, Vol. 66, pp. 8154-8159. doi:10.1021/jo010535q

[9] A. Dijksman, I. W. C. E. Arends and R. A. Sheldon, "Polymer Immobilised TEMPO (PIPO): An Efficient Catalyst for the Chlorinated Hydrocarbon Solvent-free and Bromide-free Oxidation of Alcohols with Hypochlorite," Chemical Communications, Vol. 2000, No. 4, 2000, pp. 271-272. doi:10.1039/a909690f

[10] R. Ciriminna, C. Bolm, T. Fey and M. Pagliaro, "Sol-gel Ormosils Doped with TEMPO as Recyclable Catalysts for the Selective Oxidation of Alcohols," Advanced Synthesis \& Catalysis, Vol. 344, 2002, pp. 159-163. doi:10.1002/1615-4169(200202)344:2<159::AID-ADSC1 $59>3.0 . \mathrm{CO} ; 2-\mathrm{Q}$

[11] K. Yamaguchi, K. Mori, T. Mizugaki, K. Ebitani and K. Kaneda, "Creation of a Monomeric Ru Species on the Surface of Hydroxyapatite as an Efficient Heterogeneous Catalyst for Aerobic Alcohol Oxidation," Journal of the American Chemical Society, Vol. 122, 2000, pp. 7144-7145. doi:10.1021/ja001325i

[12] G. Pozzi, M. Cavazzini, S. Quici, M. Benaglia and G. Dell'Anna, "Poly(ethylene glycol)-supported TEMPO: An Efficient, Recoverable Metal-Free Catalyst for the Selective Oxidation of Alcohols," Organic Letters, Vol. 6, No. 3, 2004, pp. 441-443. doi:10.1021/o1036398w

[13] T. Miyazawa and T. Endo, "Oxidation of Benzyl Alcohol with Fe(III) Using Polymers Containing the Nitroxyl Radical Structure as a Mediator," Journal of Polymer Science: Polymer Chemistry Edition, Vol. 23, No. 9, 1985, pp. 2487-2494. doi:10.1002/pol.1985.170230913

[14] N. E. Leadbeater and K. A. Scott, "Preparation of a Resin-bound Cobalt Phosphine Complex and Assessment of Its Use in Catalytic Oxidation and Acid Anhydride Synthesis," Journal of Organic Chemistry, Vol. 65, No. 15, 2000, pp. 4770-4772. doi:10.1021/jo0003293

[15] A. Gopinathan, N. Hisanori and K. Yasuyuki, "A Simple and Efficient Iodination of Alcohols on Polymer-supported Triphenylphosphine," Organic Process Research \& Development, Vol. 6, No. 2, 2002, pp. 190-191.
[16] J. Chen, K. S. Scott, G. H. Janathan, D. H. John, P. S. Richard and D. R. Robin, "Application of Poly(ethylene glycol)-based Aqueous Biphasic Systems as Reaction and Reactive Extraction Media," Industrial \& Engineering Chemistry Research, Vol. 43, No. 17, 2004, pp. 5358-5364. doi:10.1021/ie0341496

[17] V. A. Nair, S. M. Mustafa and S. Krishnapillai, "Polystyrene Supported Manganese Complexes: Heterogeneous Catalysts for Oxidation Reactions," Journal of Polymer Research, Vol. 10, No. 4, 2003, pp. 267-273.

[18] T. Wirth, "Hypervalent Iodine Chemistry: Modern Developments in Organic Synthesis (Series: Topics in Current Chemistry)," 1st Edition, Springer, 2003.

[19] Z. Lei, C. Denecker, S. Jegasothy, D. C. Sherrington, N. K. H. Slater and A. J. Sutherland, "A Facile Route to a Polymer-supported IBX Reagent," Tetrahedron Letters, Vol. 44, No. 8, 2003, pp. 1635-1637. doi:10.1016/S0040-4039(03)00041-8

[20] T. Zollner, P. Gebhardt, R. Beckert and C. Hertweck, "Efficient Synthesis of 9- and 13-Oxo Leucomycin Derivatives Using Hypervalent Iodine Reagents in Solution and on Solid Support," Journal of Natural Products, Vol. 68, No. 1, 2005, pp. 112-114. doi:10.1021/np049728+

[21] M. Mulbaier and A. Giannis, "Synthesis of (R)-(-)phenylpiperidin-1-yl-acetic Acid and Its Utilization for the Synthesis of (R)-(-)-bietamiverine and (R)-(-)dipiproverine," Arkivoc, Part 6, 2003, pp. 56-60.

[22] Y. Kurimura, E. Tsuchida and M. Kaneko, "Preparation and Properties of Some Water Soluble Co(III)-poly-4-vinylpyridine Complexes," Journal of Polymer Science A - I, Vol. 9, No. 12, 1971, pp. 3511-3519.

[23] H. G. Biedermann, E. Griessl and K. Wichmann, "Metallkomplexe Mit Polymeren Liganden, $3 \uparrow$. Übergangsmetallkomplexe Mit Poly(2-pyridylthylen) [Poly(2vinylpyridine)]," Die Makromolekulare Chemie, Vol. 172, No. 1, 1973, pp. 49-55.

doi:10.1002/macp.1973.021720104

[24] K. P. Dhiman, R. K. Mahajan and I. Kaur, "Synthesis of a Cellulose-Grafted Polymeric Support and Its Application in the Reductions of Some Carbonyl Compounds," Journal of Applied Polymer Science, Vol. 108, No. 1, 2008, pp. 99-111. doi:10.1002/app.27423

[25] M. Zupan, B. Šket and Y. Johar, "Synthesis and Properties of Cross-Linked 4-Vinylpyridine-Styrene-Halogen Complexes," Journal of Macromolecular Science, Part A: Chemistry, Vol. 17, No. 5, 1982, pp. 759-769.

[26] M. S. Baines, "Inorganic Redox Systems in Graft Polymerization onto Cellulosic Materials," Journal of Polymer Science, Part C: Polymer Symposia, Vol. 37, No. 1, 1972, pp. 125-151.

[27] A. P. Johnson and A. Pelter, "The Direct Oxidation of Aliphatic Iodides to Carbonyl Compounds," Journal of the Chemical Society, 1964, pp. 520-522. See also: N. Kornblum, W. J. Jones and G. J. Anderson, “A New and Selective Method of Oxidation. The Conversion of Alkyl Halides and Alkyl Tosylates to Aldehydes," Journal of 
the American Chemical Society, Vol. 81, 1959, pp. 4113-4114.

[28] B. Ganem and R. K. Jr. Boeckman, "Silver-assisted Dimethylsulfoxide Oxidations; An Improved Synthesis of Aldehydes and Ketones," Tetrahedron Letters, Vol. 15, No. 11, 1974, pp. 917-920. doi:10.1016/S0040-4039(01)82368-6

[29] V. Franzen, “Octanal,” Organic Syntheses, Coll., Vol. 5, 1973, pp. 872-874. V. Franzen and S. Otto, "Eine neue
Methode zur Darstellung von Carbonylverbindungen," Chemische Berichte, Vol. 94, No. 5, 1961, pp. 1360-1363. doi:10.1002/cber.19610940530

[30] J. M. J. Fréchet, P. Darling and M. J. Farrall, "Polymeric Reagents V. Preparation of a New Recyclable Polymeric Oxidizing Agent for the Oxidation of Halides and Tosylates into Carbonyl Compounds," Polymer Preprints, Vol. 21, No. 2, 1980, pp. 270-272. 